\title{
Heat Transfer and Friction in a Low-Aspect-Ratio Rectangular Channel with Staggered Slit-Ribbed Walls*
}

\author{
JENN-JIANG HWANG ${ }^{a, \dagger}$ and TONG-MIIN LIOU ${ }^{b}$ \\ a Department of Mechanical Engineering, Chung-Hua University, Hsinchu, Taiwan 300, ROC; \\ ${ }^{\mathrm{b}}$ Department of Power Mechanical Engineering, National Tsing-Hua University, Hsinchu, Taiwan 300, ROC
}

(Received 20 May 1997; In final form 2 July 1997)

\begin{abstract}
Fully developed heat transfer and friction in a rectangular channel with slit-ribbed walls are examined experimentally. The slit ribs are transversely arranged on the bottom and top channel walls in a staggered manner. Effects of rib open-area ratio $(\beta=24 \%, 37 \%$, and $46 \%)$, rib pitch-to-height ratio $(P i / H=10,15$ and 20$)$, and Reynolds number $(10,000 \leq$ $\boldsymbol{R e} \leq \mathbf{5 0 , 0 0 0 )}$ are examined. The rib height-to-channel hydraulic diameter ratio is fixed at $H / D e=0.081$. It is disclosed that the heat transfer coefficient for the slit-ribbed channel is higher than that for the solid-ribbed channel, and increases with rib open-area ratio. Results also show that the friction factor for the slit-ribbed channel is significantly lower than that for the solid-ribbed one. Moreover, the ribs with larger open-area ratios in a higher flow Reynolds number condition could give the better thermal performance under the constant friction power constraint. Roughness functions for friction and heat transfer are further developed in terms of rib and flow parameters.
\end{abstract}

Keywords: Slit rib, Rib open-area ratio, Thermal performance, Roughness function

\section{INTRODUCTION}

Applying rib-turbulators on the surfaces of high heat flux devices is widely considered because it provides an abundant heat transfer enhancement. The use of solid ribs has been explored for applications such as gas-cooled nuclear reactors and gas turbine blade cooling. The ribs break up the viscous sublayer and promote local wall turbulence that, in turn, increase the heat transfer from the rough as well as smooth surfaces. Inevitably, the enhance- ment in heat transfer accompanies a higher pressure drop penalty of the fluid flow. Therefore, many investigations have been conducted toward establishing an optimal rib geometry which gives the best heat transfer performance for a given pumping power. Relevant geometric parameters discussed in previous works are channel aspect ratio (Han et al., 1978), rib angle-of-attack (Han et al., 1985), rib spacing (Liou and Hwang, 1992a), rib height (Liou and Hwang, 1992b), rib shape (Liou and Hwang, 1993), and relative arrangement of ribs

* This paper was originally presented at ISTP-9.

${ }^{\dagger}$ Corresponding author. Tel.: 886-35374281 Ext. 8334. Fax: 886-35373771. E-mail: jjhwang@chu.edu.tw. 
(Lau et al., 1991). This paper concerns the effect of slit rib-turbulators on the heat transfer and friction in a rectangular channel. Slit ribs are of great interest since they provide a substantially lower drag force in comparison with solid ribs and still provide enhanced heat transfer coefficient in comparison with the smooth-walled duct. Three main issues are provided in this study. First, experiments are conducted to examine the effect of replacing conventional solid rib-turbulators by slit rib-turbulators on the heat transfer and friction in a rectangular channel. Then, by using the average heat transfer and friction data the thermal performance comparison is made between the solid- and slit-ribbed channels under the constant pumping power condition. Finally, roughness correlations of the friction and heat transfer for turbulent flows in a rectangular channel with slit ribs are developed. Based on the law-of-the-wall similarity and the application of the heat-momentum transfer analogy (Dipprey and Sabersky, 1963), the geometrically non-similar roughness parameters rib pitch-to-height ratio $\mathrm{Pi} / \mathrm{H}$ and angle-of-attack $\alpha$ have been respectively correlated into the roughness functions for turbulent flow in a tube (Webb et al., 1971) and that between parallel plates (Han et al., 1985) with repeated solid-type ribs. In the current work, this concept will be extended to correlate the data for turbulent flow in a rectangular channel with repeated slit roughness by taking into account the parameter $\beta$.

\section{DESCRIPTION OF EXPERIMENT}

The horizontal low-speed wind tunnel, as shown in Fig. 1, is operated in suction mode. Air is drawn into the settling chamber from the temperature controlled laboratory room, traverses the bell-like contraction, flows through the slit-ribbed channel, a flow straightener, a flow meter, and then is exhausted by a $3 \mathrm{hp}$ blower. The test channel is

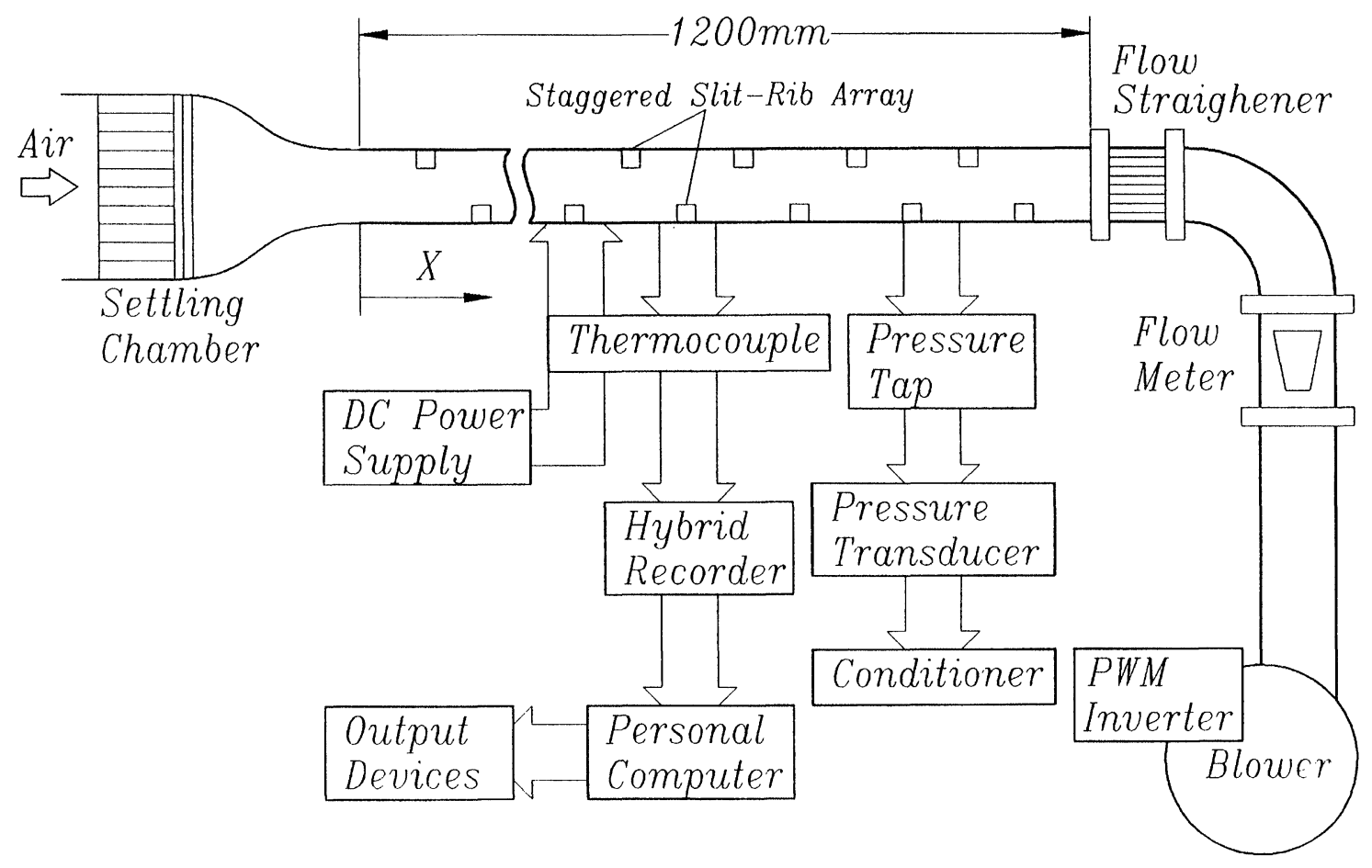

FIGURE 1 Schematic drawing of flow system and experimental apparatus. 
$1200 \mathrm{~mm}$ long and has an aspect-ratio of $4: 1$ (40 $\mathrm{mm} \times 160 \mathrm{~mm}$ for $Y-Z$ plane). The hydraulic (equivalent) diameter $(D e)$ of the test channel is $6.4 \mathrm{~mm}$. The upper and lower horizontal walls of the test section are heated, and the two vertical walls (Plexiglas plates) are thermally insulated. The configuration of the heat transfer walls is shown schematically in Fig. 2(a). Each heat transfer surface is made of a 3-mm-thick aluminum plate with a $0.18-\mathrm{mm}$-thick thermofoil. The aluminum plate is highly polished to minimize emissivity, hence radiative losses. In addition, to prevent conductive heat losses, a 6-mm-thick fiberglass board and a $20-\mathrm{mm}$-thick balsa wood are adhered uniformly on the back side of the heated plate. The aluminum slit ribs are glued staggeringly on the upper and lower channel walls in a required arrangement. The rib angle-of-attack is $90^{\circ}$. Thin layers of thermally conducting epoxy cement (electrically insulated) serve to ensure good contact between the heat transfer surfaces and ribs. Aluminum ribs are used in this study for their high thermal conductivity and machinability.

Thirty-nine copper-constantan thermocouples are located between $X / D e=12-14$ for wall surface temperature measurements. As shown in Fig. 2(a), for the baseline experiments $(P i / H=10)$, the channel wall between ribs and the rib top wall are instrumented with ten and three thermocouples, respectively. The junction-beads (about $0.15 \mathrm{~mm}$ ) of the thermocouples are carefully embedded into the walls, and then ground flat to ensure that they are flush with surfaces. In addition, one and five thermocouples are placed at the test channel inlet and exit, respectively, for the airflow temperature measurements. The temperature signals are transferred to a hybrid recorder, and subsequently sent to a PC-486 computer via a multi-I/O interface. The pre-processing of the raw data is done in a builtin BASIC program where the non-dimensional

(a)

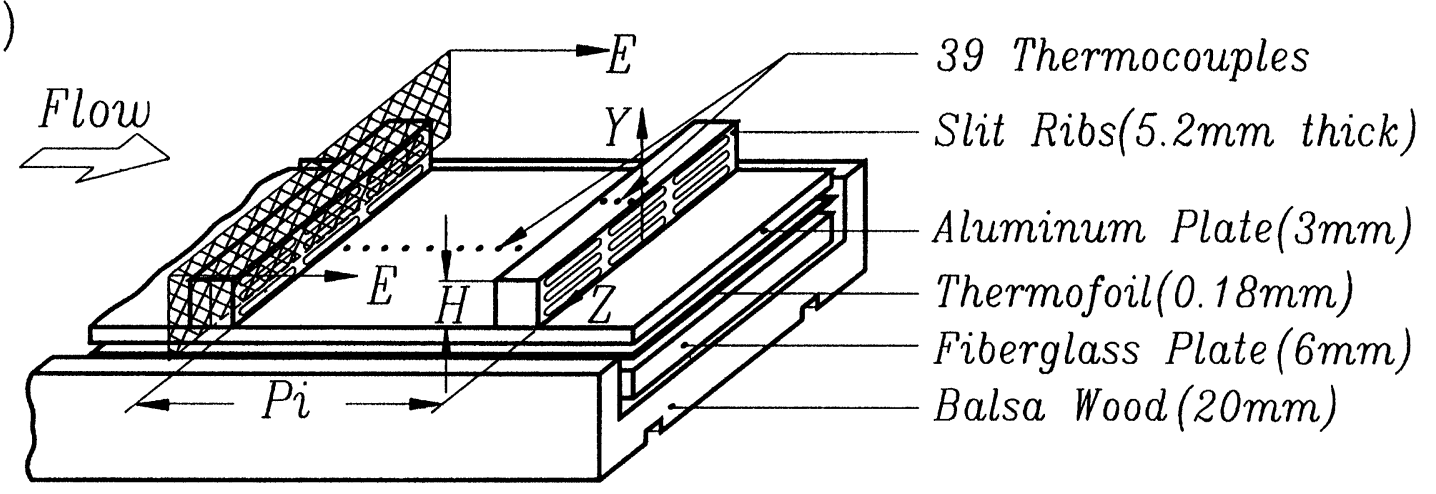

(b) Section E-E

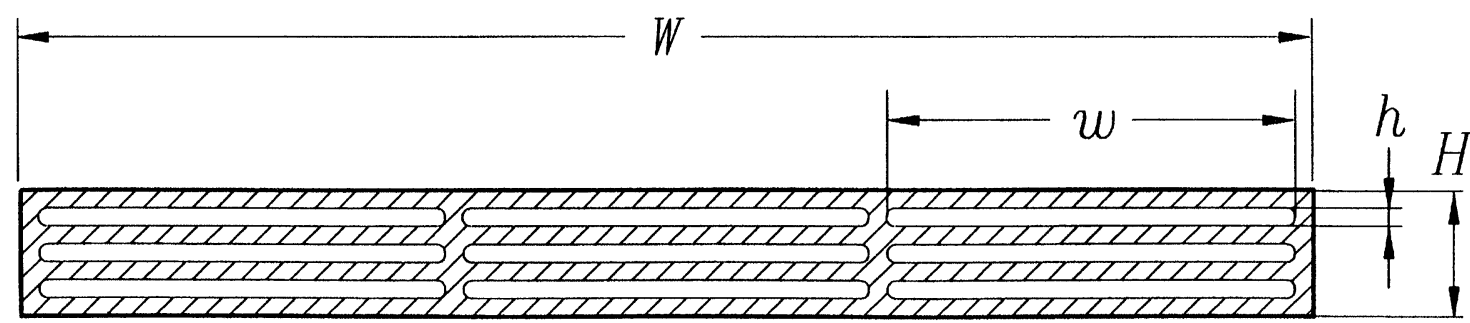

FIGURE 2 (a) Sketch of configurations of test section. (b) Dimensions of the slit rib. 
parameters are calculated. Two pressure taps situated at $X / D e=6$ and 17 measure the static pressure differences for frictional losses. A microdifferential transducer is connected to each pressure tap. The measured pressure signal is subsequently amplified to a digital readout. As shown in Fig. 2(b), a total of nine slit-slots is perforated through the aluminum rib (5.2-mm-thick) for the required open-area ratio. The open-area ratio of the slit rib is defined as $\beta=(n \cdot w \cdot h) /(W \cdot H)$, where $n$ is the number slit-slots distributed on the rib, $w$, the width of the slot, $h$, the height of the slots, $W$, the channel width, and $H$, the rib height. The rib open-area ratios investigated are $24 \%, 37 \%$, and $46 \%$. The other variable parameters investigated and compared are: rib pitch-to-height ratio, $\mathrm{Pi} / \mathrm{H}=$ 10,15 , and 20; and flow Reynolds number $10,000 \leq$ $R e \leq 50,000$

\section{DATA REDUCTION}

The convection heat transfer coefficient of the heated surface is presented in terms of the average Nusselt number $\overline{N u}$, which is defined as

$$
\begin{aligned}
\overline{N u} & =\bar{h} \cdot D e / k f=Q_{\mathrm{conv}} \cdot D e /\left[A \cdot\left(\bar{T}_{\mathrm{w}}-\bar{T}_{\mathrm{b}}\right) \cdot k_{f}\right] \\
& =\left(Q-Q_{\text {loss }}\right) \cdot D e /\left[A \cdot\left(\bar{T}_{\mathrm{w}}-\bar{T}_{\mathrm{b}}\right) \cdot k_{f}\right] .
\end{aligned}
$$

$Q_{\text {conv }}$ represents the net heat transfer rate from the ribbed wall to the coolant, and is calculated by subtracting the heat loss $\left(Q_{\text {loss }}\right)$ from the supplied electrical power $(Q)$. The electrical power generated from the thermofoil is determined from the measured thermofoil resistance and the current through the thermofoil on each surface. It is also checked by measuring voltage drop across each thermofoil. The effect of the temperature variation on the local thermofoil is calculated to be small and negligible. Thus, the thermofoil ensured a nearly uniform heat flux on each surface of the test duct. The heat loss can be estimated by the following equation:

$$
Q_{\text {loss }}=Q_{\mathrm{c}}+Q_{\mathrm{r}}+Q_{\mathrm{a}}
$$

$Q_{\mathrm{c}}$ is the conductive heat loss from the back sides of the heated plates (ribbed walls) and the vertical adiabatic plates (smooth walls) to the environment, and is estimated to be less than $3 \%$ and $6 \%$, respectively, for the range of Reynolds numbers tested. The radiative heat loss from the roughened surface to its surroundings, $Q_{\mathrm{r}}$, is evaluated by a diffuse gray-surface network (Siegel and Howell, 1981), and is less than $0.5 \%$ of the total electrical power input. $Q_{\mathrm{a}}$ is the axial conductive heat loss through upstream and downstream ends of the heated plates and is estimated to be less than $1 \%$ of the total electrical power input for Reynolds number larger than 10,000. The energy conservation is further checked by comparing the total net heat transfer rate from the test channel to the cooling air $\left(Q_{\text {conv }}\right)$ with the cooling air enthalpy rise along the test channel. Results show that only $5 \%$ in discrepancy is found between these two methods. To place the results on a common basis the heat transfer area $(A)$ in Eq. (1) serves as the projected area of the corresponding ribless wall. The wall temperature, $\bar{T}_{\mathrm{w}}$ is the average value of the outputs of the 39 thermocouples and could be read from the hybrid recorder directly. The bulk mean air temperature $\left(\bar{T}_{\mathrm{b}}\right)$ is calculated from the measured channel inlet and outlet air temperature by assuming a linear rise along the test channel. As estimation by the method of Kline and McClintock (1953) the maximum uncertainty of the Nusselt number is less than $6.6 \%$ for Reynolds number larger than 10,000 .

The friction factor of the periodic fully developed flow is calculated from the pressure drop across the test duct and the mean velocity of the air and expressed as

$$
f=[(-\Delta P / \Delta X) \cdot D e] /\left(\rho \cdot U^{2} / 2\right),
$$

where the pressure gradient, $\Delta P / \Delta X$, is evaluated by taking the ratio of the pressure difference and the distance of two pressure taps. The maximum uncertainty of $f$ is estimated to be less than $7.3 \%$ for Reynolds number greater than 10,000 by the uncertainty estimation method of Kline and McClintock (1953). 
The friction data for turbulent flow in a rectangular duct with two opposite ribbed walls can be correlated by the modified equations (Han, 1988; Liou and Hwang, 1993):

$$
\begin{aligned}
R\left(H^{+}\right)= & (f / 8)^{-1 / 2} \\
& +2.5 \ln \{(2 H / D e)[2 W /(W+B)]\}+2.5,
\end{aligned}
$$

where

$$
H^{+}=(H / D e) \operatorname{Re}(f / 8)^{1 / 2} .
$$

Similarly, heat transfer data for fully developed turbulent flow in a rectangular duct with two opposite ribbed walls can be correlated by the following equations (Han, 1988; Liou and Hwang, 1993):

$$
G\left(H^{+}, P r\right)=(f / 8)^{1 / 2} / S t+2.5 \ln (2 H / D e)+2.5 \text {. }
$$

In the present data reduction program, Eqs. (4)(6) are used to calculate the friction roughness function $R\left(H^{+}\right)$and the heat transfer roughness function $G\left(H^{+}, P r\right)$.

\section{EXPERIMENTAL RESULTS AND DISCUSSION}

\section{Average Heat Transfer Coefficients and Friction Factors}

Figure 3 gives the average Nusselt number ratio of the slit-ribbed walls as a function of Reynolds number, where $\overline{N u}_{\mathrm{s}}$ is obtained from the DittusBoelter correlation. The solid line is the results of the solid-ribbed wall (Hwang and Liou, 1995). It can be observed from this figure that for all of the rib open-area ratios investigated the heat transfer augmentation $\left(\overline{N u} / \overline{N u}_{\mathrm{s}}>1\right)$ is achieved. The average Nusselt number ratios for both the slit- and the solid-ribbed walls decrease with increasing Reynolds number. It is also found that the increment of the average Nusselt number ratios for the slit-ribbed wall is higher than that of the

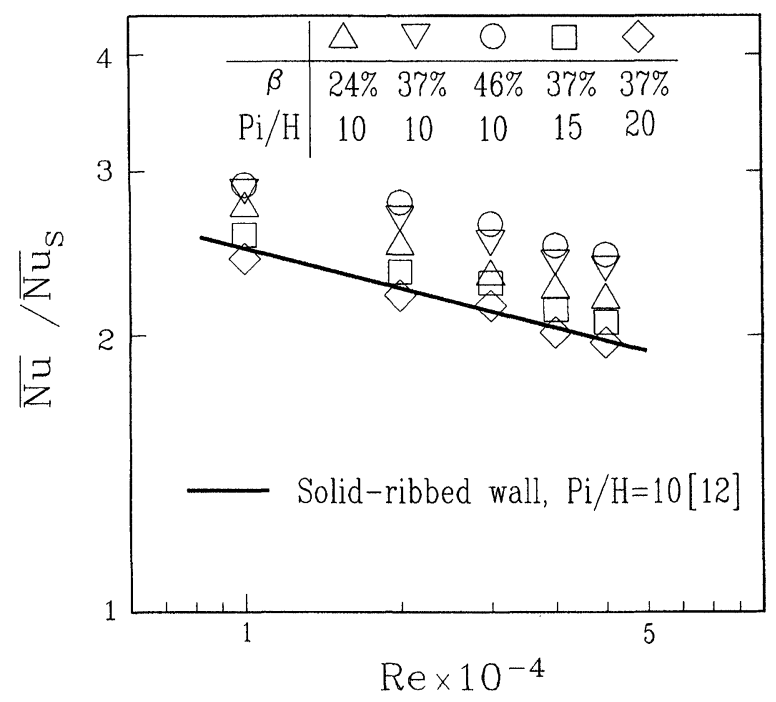

FIGURE 3 Average Nusselt number ratio vs. Reynolds number.

solid-ribbed wall, and increases with increasing the rib open-area ratio. For a given Reynolds number, the level of the heat transfer augmentation of the slit-ribbed wall is about $8 \%, 20 \%$, and $35 \%$ higher than that of the solid-ribbed wall, respectively, for $\beta=24 \%, 37 \%$, and $46 \%$ at $P i / H=10$. The higher heat transfer enhancement accompanied by the slitribbed wall may be due to the combined factors of the higher turbulent mixing of multijet-streams after the slit rib and the higher heat transfer surface area as flow through the slit ribs. It is interesting to note that the slit rib has about 2.3-fold heat transfer surface area as compared with the solid rib.

Figure 4 illustrates the effects of rib open-area ratio and flow Reynolds number on the friction factor for the slit-ribbed geometry. The rib height is fixed at $H / D e=0.081$. The pressure drops across the test channel are measured by the unheated flow conditions. It is seen from this figure that the friction factor for the slit-ribbed channel is higher than its counterpart for the smooth channel (dashedline, Blasius correlation), but lower than that for the solid-ribbed channel (dotted line, Hwang and Liou, 1995). It is almost independent of the Reynolds number. In comparison with the results of the channel flows with solid ribs, the values of $f$ are 


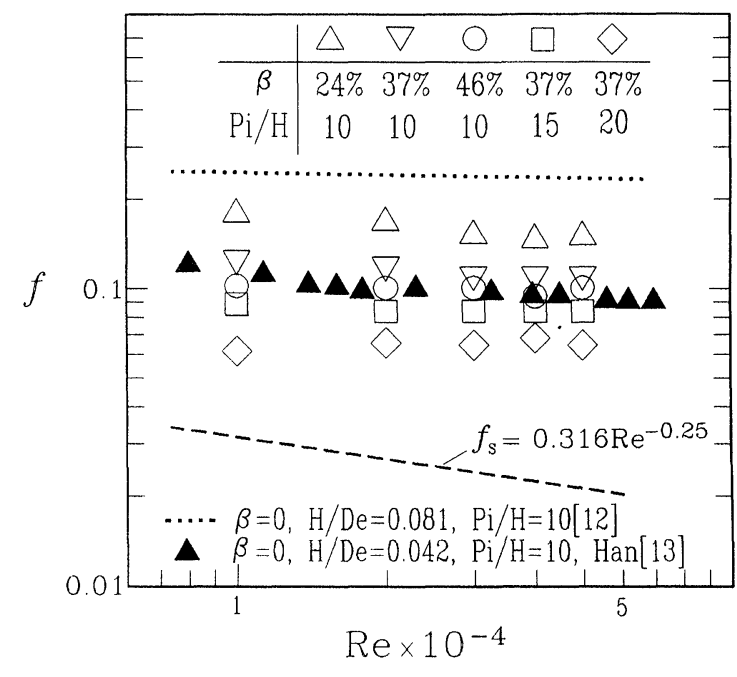

FIGURE 4 Friction factor vs. Reynolds number.

approximately $84 \%, 72 \%$, and $60 \%$ for $\beta=24 \%$, $37 \%$, and $46 \%$, respectively, in the range of the Reynolds number investigated. As expected, for a given Reynolds number the friction factor decreases with increasing $\beta$ because of the less cross-sectional blockage for ribs with the larger $\beta$. A comparison of the present data with those in the previous work is also made in Fig. 4. In Han's work (Han, 1984), solid ribs with $H / D e=0.042$ were arranged on the two opposite channel walls. The channel blockage is largely similar to that of the present slit-ribbed channel with $H / D e=0.081$ and $\beta=46 \%$. It is found that a good agreement is achieved between the present and Han's works.

\section{Thermal Performance}

In practical applications, the thermal performance based on unit pumping (or blowing) power is widely considered. Although, the heat transfer could be enhanced with ribs applying on the channel wall, the pressure loss is inevitably increased. To keep. the fluid pumping power constant, the flow velocity must be reduced. Subsequently the average Nusselt number is reduced. Fortunately, this reduction can sometime be overcome by heat transfer enhancement which is given by rib-turbulators. The relationship of the ribbed and smooth channels for the

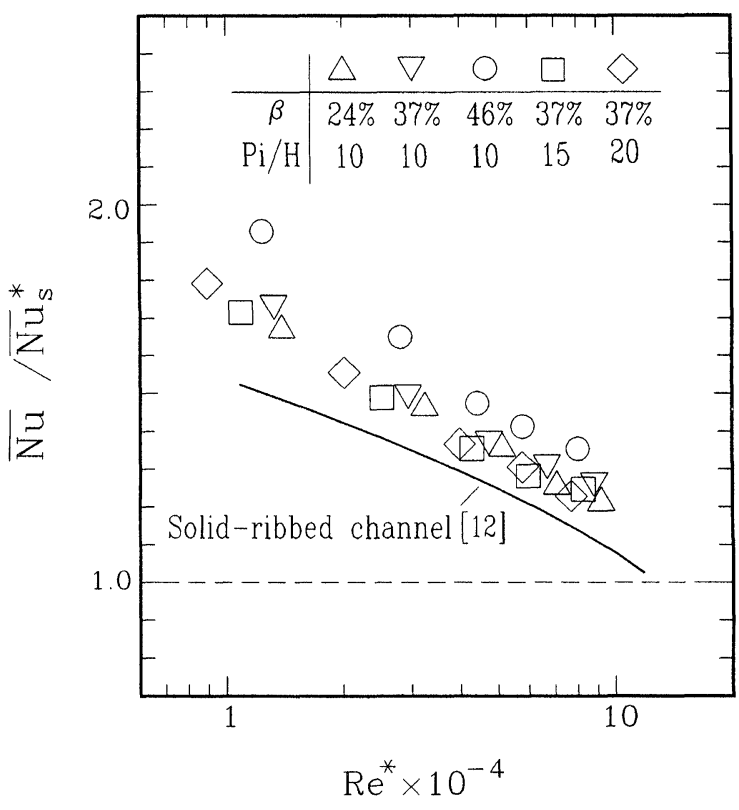

FIGURE 5 Thermal performances of the ribbed channels under constant pumping power condition.

same pumping power has been described in detail in Hwang and Liou (1995). The pumping power required to feed the fluid through the channel is proportional to $f \cdot R e^{3}$. Thus in Fig. 5 the performance shown by the ratio of $\overline{N u} / \overline{N u}_{\mathrm{s}}^{*}$ is plotted against $\left(f / f_{\mathrm{s}}\right)^{1 / 3} \cdot \operatorname{Re}$ (denotes as $R e^{*}$ in Fig. 5), where $\overline{N u}_{\text {s }}^{*}$ is the average Nusselt number for a smooth channel with the flow rate at which the pumping power is the same as that obtained in a ribbed channel. Figure 5 shows that the improvement in Nusselt number ratio of the slit-ribbed channel is more pronounced than that of the solidribbed channel (solid line, Hwang and Liou, 1995), especially for the larger rib open-area ratio. At lower Reynolds number both the slit- and solidribbed geometries perform better than those at higher Reynolds number. Therefore, the usage of the slit ribs with the large rib open-area ratios in the low Reynolds number range is recommended.

\section{Roughness Functions}

For the results of the rectangular channel with slit turbulence promoters to be most useful for 
designers, general correlations are required for both the heat transfer and friction over a wide range of rib and flow parameters. According to the friction similarity law derived in Eq. (4), the measured average friction factor, the rib height-tochannel hydraulic diameter ratio, channel aspect ratio, and Reynolds number could be correlated with the friction roughness function $R\left(H^{+}\right)$. In this work, both the geometrically non-similar parameters, $P i / H$ and $\beta$, are taken into account, where $\beta$ has not been considered in the past. As shown in Fig. 6(a), the correlation of the friction roughness function $R$ can be written as

$$
R=3.25[(P i / H) / 10]^{0.53}(1-\beta)^{-0.81}
$$

The deviation of Eq. (7) is $5 \%$ for $95 \%$ of the data shown in Fig. 6(a). Note that $R$ in the above equation is highly dependent on $P i / H$ and $\beta$ but independent of $\mathrm{H}^{+}$, which implies that the

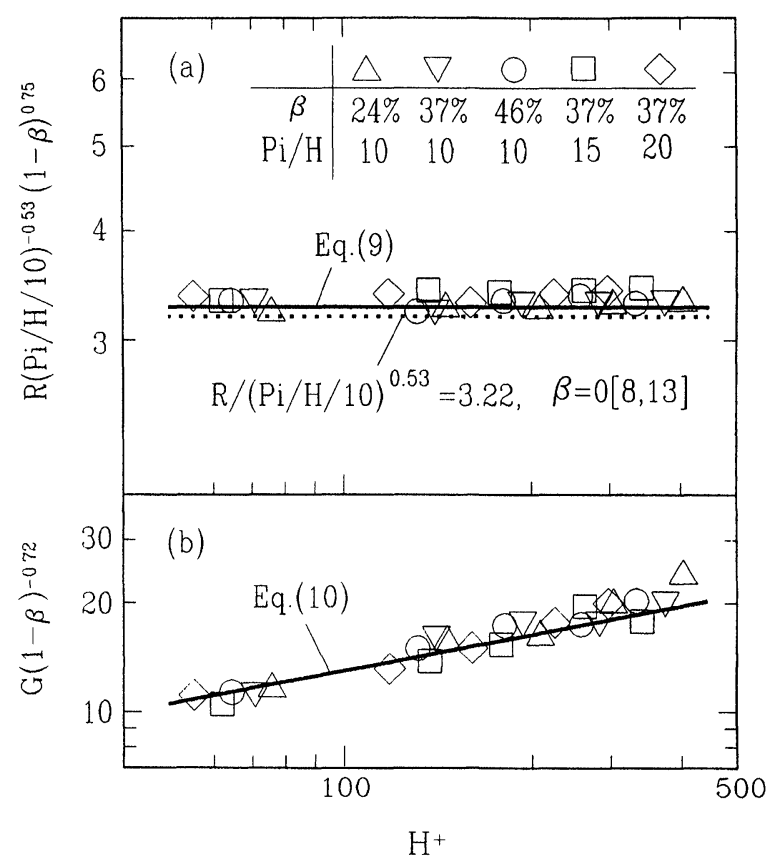

FIGURE 6 Roughness friction and heat transfer parameters vs. roughness friction function. average friction factor keeps a constant value as the Reynolds number is varied. Figure 6(a) further shows the comparison of the present friction results with the previous correlations of the solid-ribbed geometries (Webb et al., 1971; Hwang and Liou, 1995). Basically, these correlations are largely identical with regardless of the effect of the rib openarea ratio. The values of $R$ given in Eq. (7) for the slit-ribbed geometry is significantly higher than those of the solid-ribbed geometry, which confirms that the lower pressure drop is accompanied by the slit-ribbed geometry. After $R$ is correlated experimentally from Eq. (7), the friction factor can be predicted by the following procedure. As $\beta$ and $\mathrm{Pi} / \mathrm{H}$ are given, the roughness friction function is determined by Eq. (7), and subsequently the friction factor can be predicted by Eq. (6) for a given rib height and channel aspect ratio.

Similarly, in accordance with the heat transfer similarity law derived in Eq. (5), the measured average Nusselt number, the average friction factor $f$, and $R$ could be correlated with the heat transfer roughness function $G\left(H^{+}, P r\right)$. For a Prandtl number of 0.703 of the present study, the correlation of $G$ shown in Fig. 6(b) can be represented by

$$
G=2.8\left(H^{+}\right)^{0.35}(1-\beta)^{-0.81} .
$$

The deviation of Eq. (8) is $8 \%$ for $95 \%$ of the data shown in Fig. 6(b). The equation shows a significant dependence of $G$ on $H^{+}$and $\beta$. After the heat transfer roughness function is correlated experimentally from Eq. (8), the average heat transfer coefficient can be predicted by combining Fig. 6(b), and Eqs. (4), (6), and (8) for a given $H / D e, P i / H$, $\beta$, and $R e$.

The above heat transfer and friction correlations are valid for the slit-rib geometry with the parameters ranges $10 \leq P i / H \leq 20,24 \% \leq \beta \leq 46 \%$, $10,000 \leq R e \leq 50,000, \alpha=90^{\circ}, W / B=4.0, H / D e=$ 0.081 , and $P r=0.703$. These correlations may be useful in the design of the related devices such as heat exchangers, electric cooling package, and turbine blade cooling channel. 


\section{SUMMARY AND CONCLUSIONS}

The effect of slit ribs on the fully developed heat transfer and friction factor in a low-aspect-ratio rectangular channel has been examined experimentally. The slit ribs are attached staggeringly on the ceiling and bottom walls of the channel. As compared with the conventional solid-ribbed geometry, the slit-ribbed geometry yields a higher heat transfer enhancement and pays a lower pressure drop penalty at the same rib height and spacing. The friction factor decreases as the rib open-area ratio is increased, whereas the opposed trend is true for the average Nusselt number. Performance comparisons reveal that the slit with larger rib open-area ratios in a higher Reynolds number range could perform the superior heat transfer enhancement under the same pumping power condition. Based on the law of the wall similarity and the application of heat-momentum transfer analogy, general friction and heat transfer correlations have been developed by taking into account of rib spacing, open-area ratio, and flow Reynolds number, where the geometrically non-similar parameter, $\beta$, has not been considered in the past.

\section{NOMENCLATURE}

\begin{tabular}{|c|c|}
\hline 4 & heat transfer area \\
\hline$B$ & height of the channel \\
\hline De & hydraulic diameter \\
\hline$f$ & friction factor for the ribbed duct \\
\hline$f_{\mathrm{s}}$ & friction factor for the smooth duct \\
\hline$H$ & rib height \\
\hline$h$ & slit height \\
\hline $\bar{h}$ & average heat transfer coefficient \\
\hline$k_{f}$ & air conductivity \\
\hline$\frac{\sigma}{N u}$ & $\begin{array}{l}\text { average Nusselt number for periodically } \\
\text { fully developed ribbed duct flow, } \bar{h} D e / k_{f}\end{array}$ \\
\hline$\overline{N u}_{\mathrm{s}}$ & $\begin{array}{l}\text { average Nusselt number for the smooth } \\
\text { duct at the same flow rate as the } \\
\text { rib-roughened duct }\end{array}$ \\
\hline$\overline{N u}_{\mathrm{s}}^{*}$ & $\begin{array}{l}\text { average Nusselt number for the smooth } \\
\text { duct at the same pumping power as the } \\
\text { rib-roughened duct. }\end{array}$ \\
\hline
\end{tabular}

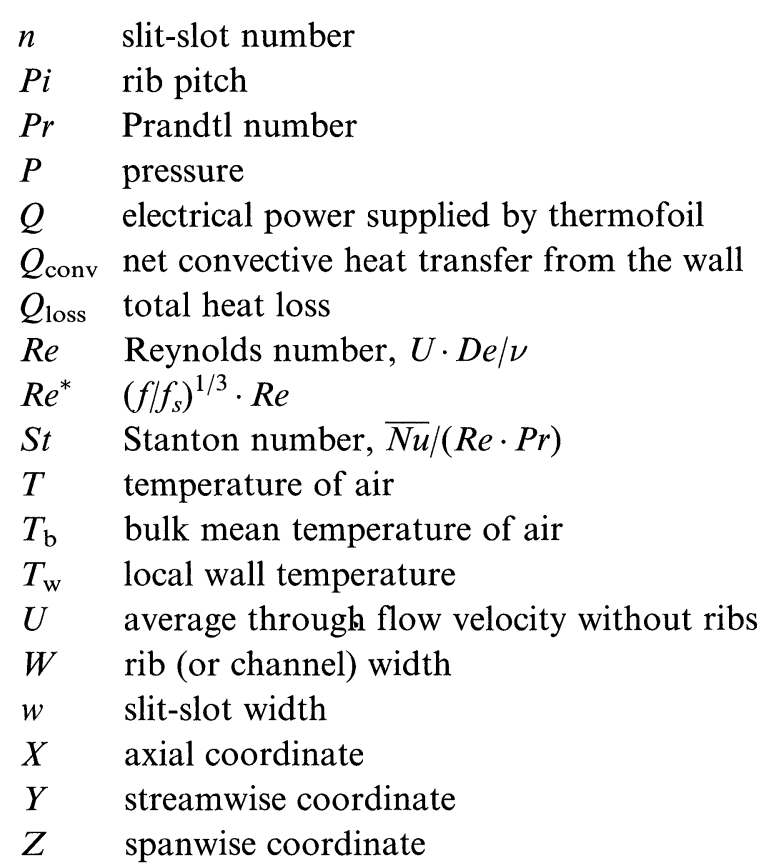

\section{Greek Symbols}

$\beta \quad$ perforated rib open-area ratio $\rho \quad$ air density

\section{Subscripts}

$\begin{array}{ll}\text { b } & \text { bulk mean } \\ \mathrm{s} & \text { smooth } \\ \mathrm{W} & \text { wall }\end{array}$

\section{Acknowledgements}

Support for this work was provided by the National Science Council of the Republic of China under contract No. NSC 85-2212-E-216-003.

\section{References}

Dipprey, D.F. and Sabersky, R.H., 1963, Heat and momentum transfer in smooth and rough tubes at various Prandtl numbers, Int. J. Heat Mass Transfer, 6, 329-353.

Han, J.C., Glicksman, L.R. and Rohsenow, W.H., 1978, An investigation of heat transfer and friction for rib-roughness surfaces, Int. J. Heat Mass Transfer, 21, 1143-1156.

Han, J.C., 1984, Heat transfer and friction in channels with two opposite rib-roughened walls, Trans. ASME, Journal of Heat Transfer, 106, 774-781.

Han, J.C., Park, J.S. and Lei, C.K., 1985, Heat transfer enhancement in channels with turbulence promoters, Trans. ASME, J. Heat Transfer, 107, 628-635. 
Han, J.C., 1988, Heat transfer and friction characteristics in rectangular channels with rib turbulators, Trans. ASME, J. Heat Transfer, 110, 321-328.

Hwang, J.J. and Liou, T.M., 1995, Effect of permeable ribs on turbulent heat transfer and friction in a rectangular channel, Trans. ASME, J. Turbomachinery, 117, 265-271.

Kline, S.J. and McClintock, F.A., 1953, Describing uncertainties on single-sample experiments, Mechanical Engineering, $57,3-8$.

Lau, S.C., McMillin, R.D. and Han, J.C., 1991, Turbulent heat transfer and friction in a square channel with discrete rib turbulators, Trans. ASME, J. Turbomachinery, 113, 360-366.

Liou, T.M. and Hwang, J.J., 1992a, Turbulent heat transfer and friction in periodic fully developed channel flows, Trans. ASME, J. Heat Transfer, 114, 56-64.
Liou, T.M. and Hwang, J.J., 1992b, Developing heat transfer and friction in a rectangular ribbed duct with flow separation at inlet, Trans. ASME, J. Heat Transfer, 114, 565-673.

Liou, T.M. and Hwang, J.J., 1993, Effects of ridge shapes on turbulent heat transfer and friction in a rectangular channel, Int. J. Heat Mass Transfer, 36, 931-940.

Siegel, R. and Howell, J.R., 1981, Thermal Radiation Heat Transfer, 2nd ed., McGraw-Hill, New York.

Webb, R.J., Eckert, E.R.G. and Goldstein, R.J., 1971, Heat transfer and friction in tubes with repeated-ribs roughness, Int. J. Heat Mass Transfer, 14, 601-617. 


\section{ait \\ ENERGY MATERIALS}

M A N E Y publishing

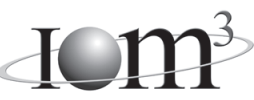

\section{Materials Science \& Engineering for Energy Systems}

Maney Publishing on behalf of the Institute of Materials, Minerals and Mining

The Institute of Materials, Minerals \& Mining

Economic and environmental factors are creating ever greater pressures for the efficient generation, transmission and use of energy. Materials developments are crucial to progress in all these areas: to innovation in design; to extending lifetime and maintenance intervals; and to successful operation in more demanding environments. Drawing together the broad community with interests in these areas, Energy Materials addresses materials needs in future energy generation, transmission, utilisation, conservation and storage. The journal covers thermal generation and gas turbines; renewable power (wind, wave, tidal, hydro, solar and geothermal); fuel cells (low and high temperature); materials issues relevant to biomass and biotechnology; nuclear power generation (fission and fusion); hydrogen generation and storage in the context of the 'hydrogen economy'; and the transmission and storage of the energy produced.

As well as publishing high-quality peer-reviewed research, Energy Materials promotes discussion of issues common to all sectors, through commissioned reviews and commentaries. The journal includes coverage of energy economics and policy, and broader social issues, since the political and legislative context influence research and investment decisions.

\section{CALL FOR PAPERS}

Contributions to the journal should be submitted online at http://ema.edmgr.com

To view the Notes for Contributors please visit: www.maney.co.uk/journals/notes/ema

Upon publication in 2006, this journal will be available via the Ingenta Connect journals service. To view free sample content online visit: www.ingentaconnect.com/content/maney

For further information please contact:

Maney Publishing UK

Tel: +44 (0)113 2497481 Fax: +44 (0)1132486983 Email: subscriptions@maney.co.uk

or

Maney Publishing North America

Tel (toll free): 8662975154 Fax: 6173546875 Email: maney@maneyusa.com

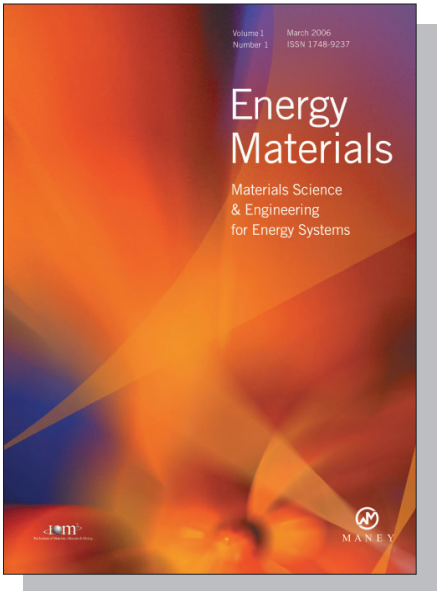

EDITORS

Dr Fujio Abe

NIMS, Japan

Dr John Hald, IPL-MPT, Technical University of Denmark, Denmark

Dr R Viswanathan, EPRI, USA

\section{SUBSCRIPTION INFORMATION}

Volume 1 (2006), 4 issues per year

Print ISSN: 1748-9237 Online ISSN: 1748-9245

Individual rate: $£ 76.00 / U S \$ 141.00$

Institutional rate: $£ 235.00 /$ US $\$ 435.00$

Online-only institutional rate: $£ 199.00 / U S \$ 367.00$

For special $\mathrm{IOM}^{3}$ member rates please email

subscriptions@maney.co.uk

\section{For further information or to subscribe online please visit www.maney.co.uk}



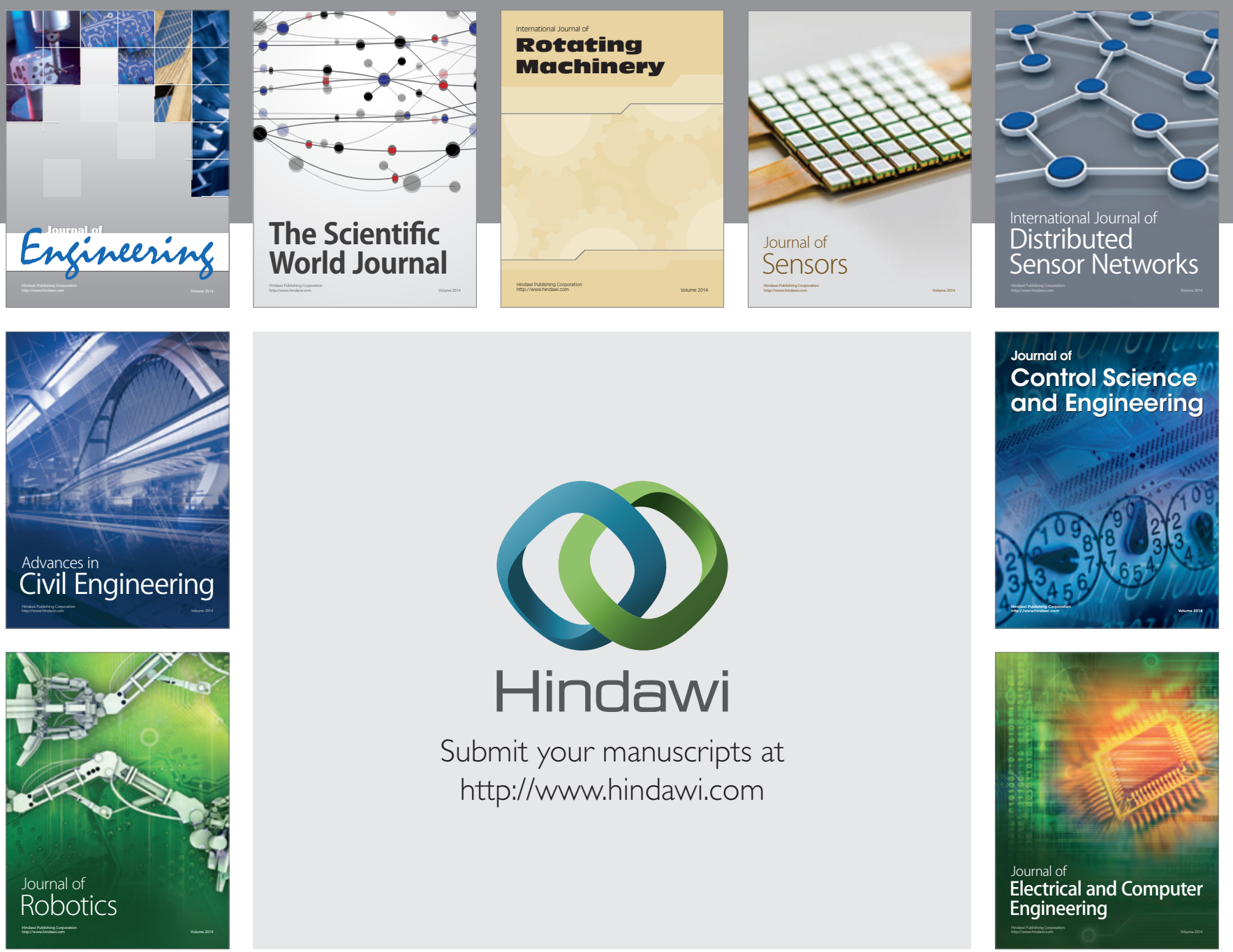

Submit your manuscripts at

http://www.hindawi.com
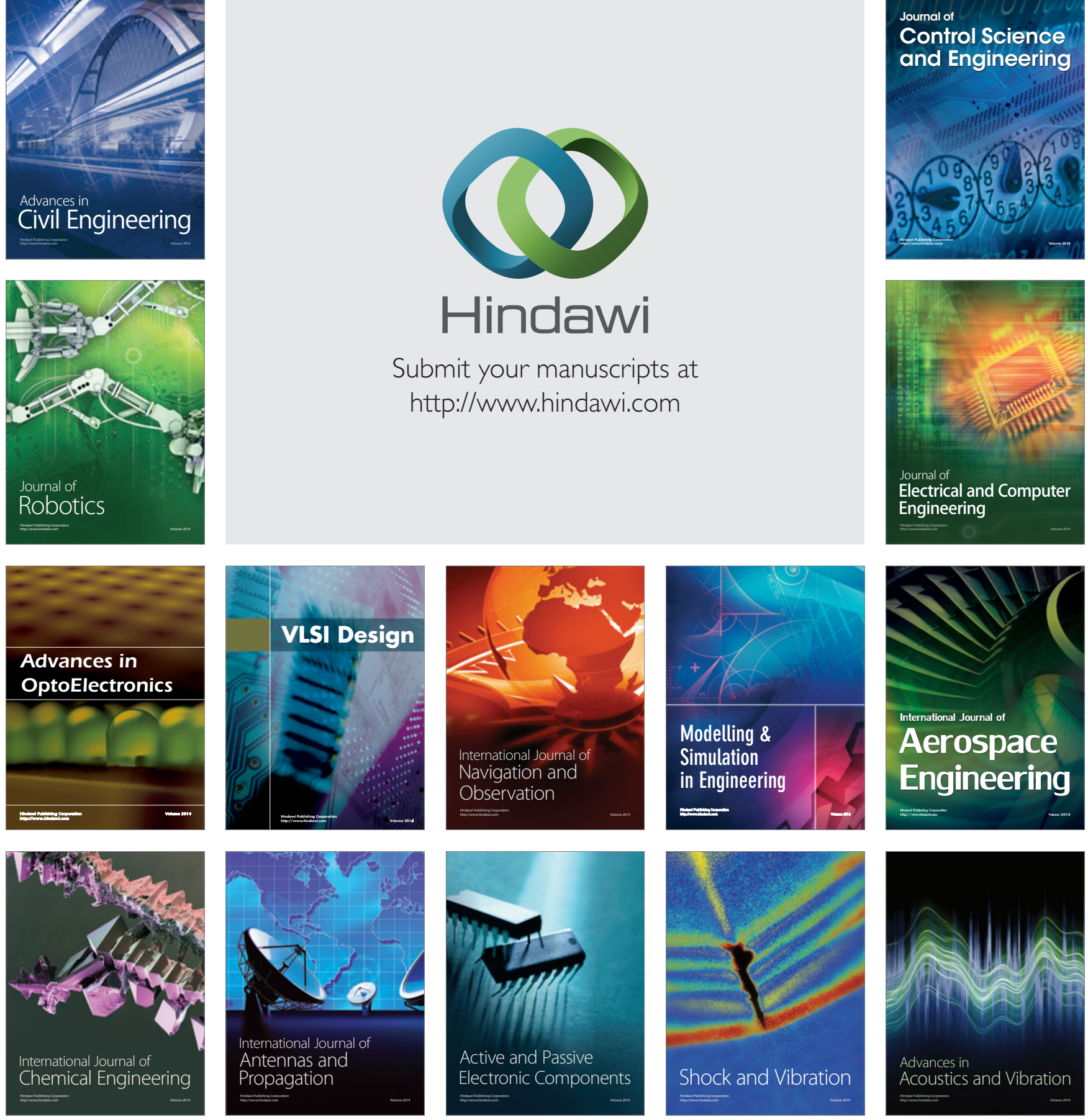